\title{
Concurrent isolation of hepatic stem cells and hepatocytes from the human liver
}

\author{
Serene M. L. Lee ${ }^{1}$ (D) Cristina Bertinetti-Lapatki ${ }^{2} \cdot$ Tobias S. Schiergens $^{1} \cdot$ Karl-Walter Jauch $^{3} \cdot$ Adrian B. Roth $^{2}$. \\ Wolfgang E. Thasler ${ }^{1,4}$
}

Received: 19 November 2019 / Accepted: 27 January 2020 / Published online: 27 March 2020 / Editor: Tetsuji Okamoto

(C) The Author(s) 2020

\begin{abstract}
Hepatocytes differentiated from induced pluripotent stem cells or stem cells have the potential to be representative in vitro models of the human liver for research as well as early safety assessment programs. However, up until now, there has been no definitive proof that differentiated hepatocytes recapitulate the phenotype and functional characteristics of primary hepatocytes from the same individual. Thus, a method for the concurrent isolation of hepatocytes and hepatic stem cells is presented here to provide the cells necessary for the evaluation of the required benchmarking. The method presented here generated high-quality hepatocytes with a purity of $94 \pm 1 \%$ and a high percentage viability of $79 \pm 2 \%$. Furthermore, the hepatic stem cells isolated were found to be actively proliferating and have a purity of $98 \pm 1 \%$. Thus, these isolated cells can be used as a powerful tool for the validation of differentiated hepatocyte in vitro models.
\end{abstract}

Keywords Hepatic stem cells $\cdot$ Hepatic progenitor cells $\cdot$ Hepatocytes $\cdot$ Liver cell isolation $\cdot$ Liver in vitro model

\section{Introduction}

The cost of bringing a new drug to market has skyrocketed mainly due to the outlay on phase 2 and 3 trials and late-stage failures (Orloff et al. 2009). Reducing late-stage drug attrition costs can best be done by early safety assessment programs. Currently, human primary hepatocytes are used as the "gold standard" in vitro model in such programs. While this model has many advantages, its usage also brings substantial challenges in a pharmaceutical environment. These challenges include limited quantity available, lack of availability when required, variable quality of hepatocytes dependent on the tissue quality or isolation procedures, uncharacterised enzymatic profiles when cells are received and long waiting times for a specific donor profile. Thus, it is very important to establish an equivalent in vitro human model without these disadvantages.

Serene M. L. Lee, Cristina Bertinetti-Lapatki, Adrian B. Roth and Wolfgang E. Thasler contributed equally to this work.

Serene M. L. Lee

Serene.Lee@med.uni-muenchen.de

Cristina Bertinetti-Lapatki

cristina.bertinetti-lapatki@ roche.com

Tobias S. Schiergens

Tobias.Schiergens@med.uni-muenchen.de

Karl-Walter Jauch

Karl-Walter.Jauch@med.uni-muenchen.de

Adrian B. Roth

adrian_b.roth@roche.com

Wolfgang E. Thasler

wolfgang.thasler@swmbrk.de
1 Department of General, Visceral and Transplant Surgery, Ludwig-Maximilians-University Munich, 5H 02 Room 428, Marchioninistr. 15, 81377 Munich, Germany

2 F. Hoffmann-La Roche Ltd, Pharmaceutical Sciences, Roche Innovation Centre, Grenzacherstr 124, 4070 Basel, Switzerland

3 Medical Directorate, Ludwig-Maximilians-University Munich, Marchioninistr. 15, 81377 Munich, Germany

4 Department of General Visceral and Minimally Invasive Surgery, Red Cross Hospital Munich, Nymphenburger Str. 163, 80634 Munich, Germany 
The use of hepatocytes differentiated from induced pluripotent stem cells (iPSC) could be an ideal solution as such hepatocytes could potentially provide unlimited in vitro models with pre-characterised and desired phenotypic backgrounds. Moreover, it offers the opportunity to include different disease phenotypes in drug toxicity testing. However, despite many attempts over the years to generate hepatocytes from iPSCs (iPSC-Heps), no iPSC-Heps representative of donor phenotype has been produced to our knowledge.

One of the reasons for this difficulty is obtaining a mature and stably differentiated phenotype. Generating iPSCs from Hepatic Stem Cells (HSCs) could help with this problem. Hepatic stem cells in this text refer to selfrenewing cells that have the potential to give rise to both hepatocytes and cholangiocytes (Schmelzer et al. 2007). The actual nomenclature to be used, whether the term HSC or hepatic progenitor cell is still unclear and controversial in the literature. The reasons that we choose to isolate HSCs in particular are manifold. Firstly, iPSCs generated from bipotential HSCs could retain a transient transcriptional memory that facilitates differentiation into hepatocytes especially at lower passage numbers (Lee et al. 2012). Secondly, unlike hepatocytes, HSCs can proliferate in culture and this could promote the formation of induced pluripotent stem cells (Panopoulos et al. 2012). Thirdly, if reprogramming to iPSCs is not desired, hepatocytes can be directly differentiated from HSCs, which have been shown to be able to persist in culture for up to 100 passages over 2 yr (Wang et al. 2010). The ability to keep HSCs in long-term culture will also allow investigators to examine differences due to reprogramming and the influence of long-term culture with or without reprogramming on subsequent differentiation to hepatocytes. Previously published works show that Epithelial Cell Adhesion Molecule (EpCAM), a transmembrane glycoprotein, is an extracellular marker expressed by HSCs (Schmelzer et al. 2007; Okabe et al. 2009) and this marker will be targeted for the isolation of HSCs in this work.

The other major reason that has made it impossible to say if differentiated hepatocytes have been successfully produced was the lack of primary hepatocytes from the same donor for benchmarking. Until today, almost all previous studies have compared functional properties of differentiated hepatocytes, such as cytochrome P450 enzyme activities, against other less relevant cell types such as undifferentiated iPSCs, early stages of differentiating stem cells or hepatic cell lines (Ulvestad et al. 2013). However, this strategy of comparing against cell types with little or no mature hepatocyte characteristics does not allow a conclusion that the donor phenotype as seen in the primary hepatocytes has been recreated.

Therefore, this study aims to provide a powerful tool to researchers to address these issues by providing a method to isolate HSCs and hepatocytes from the same donor.

\section{Materials and Methods}

Isolation of hepatocytes and hepatic stem cells Pieces of macroscopically normal liver with 1 sectioned surface from donors undergoing elective surgeries for secondary metastasis to the liver were included in this study. The liver samples were provided double-coded by the Biobank under the administration of the Human Tissue and Cell Research (HTCR) Foundation at the Ludwig-Maximilians-University (LMU). The framework of the HTCR Foundation, which includes written informed consent from all donors, has been approved by the ethics commission of the Faculty of Medicine in the LMU (number 025-12) and the Bavarian State Medical Association (number 11142).

A modified (Lee et al. 2013) two-step collagenase perfusion technique (Lee et al. 2013; Berry and Friend 1969; Seglen 1973) was used to prepare a cell suspension containing human hepatocytes and HSCs. In brief, irrigation cannulas with olive tips were inserted snugly into the larger blood vessels on the cut face of the piece of the liver for perfusion at $37^{\circ} \mathrm{C}$. The liver was perfused sequentially with perfusion buffer (154 mM sodium chloride, $20 \mathrm{mM}$ HEPES, $5.6 \mathrm{mM}$ potassium chloride, $5 \mathrm{mM}$ glucose and $25 \mathrm{mM}$ sodium hydrogen carbonate), perfusion buffer containing $1 \mathrm{mM}$ EGTA, perfusion buffer containing $5 \mathrm{mM}$ calcium chloride dihydrate and finally perfusion buffer containing $5 \mathrm{mM}$ calcium chloride dihydrate and 250 to $400 \mathrm{U} \mathrm{ml}^{-1}$ collagenase (Nordmark Biochemicals, Uetersen, Germany). Enzymatic digestion with collagenase was carried out in a recirculating manner for 9 to 12 min or until the liver is sufficiently digested. The liver piece was then placed carefully in a crystallising dish for removal of the Glisson's capsule before gently shaking the cells loose. The cell suspension was then filtered through a $210-\mu \mathrm{m}$ nylon mesh followed by a 70- $\mu$ m nylon mesh.

After filtration, the cell suspension was centrifuged at $72 g$ for $5 \mathrm{~min}$ at $4^{\circ} \mathrm{C}$. The first supernatant obtained, which contained the HSCs, was transferred to new centrifuge tubes and set on ice for the subsequent isolation of HSCs. The hepatocyte pellet was resuspended in wash buffer $(120 \mathrm{mM}$ sodium chloride, $10 \mathrm{mM}$ HEPES, $0.9 \mathrm{mM}$ calcium chloride dihydrate, $6.2 \mathrm{mM}$ potassium chloride and $0.1 \% \mathrm{w} / v$ albumin) for hepatocyte isolation.

To complete hepatocyte isolation, the hepatocytes were washed by centrifugation at $72 \mathrm{~g}$ for $5 \mathrm{~min}$ at $4^{\circ} \mathrm{C}$ followed by aspirating off the wash buffer in the supernatant and topping up the centrifuge tube with fresh wash buffer. The above washing step was repeated twice. On the last centrifugation step, the hepatocytes were resuspended in the appropriate cell culture media for a haemocytometer-based trypan blue exclusion assay to determine hepatocyte yield and viability. At this stage, the purified hepatocytes can be used in suspension or adhered to collagen-coated plates for further experiments. For adherence to 6-well Biocoat ${ }^{\mathrm{TM}}$ collagen 1-coated 
plates (Corning, Corning, NY), 1.2 million hepatocytes in hepatocyte cell culture media were added per well. These hepatocytes were allowed to adhere for $4 \mathrm{~h}$ in an incubator at $37^{\circ} \mathrm{C}$. Thereafter, a media change was carried out to remove any non-adhered cells. The hepatocyte culture medium used was DMEM media supplemented with $800 \mu \mathrm{g} / \mathrm{l}$ hydrocortisone, $125 \mathrm{U} / \mathrm{l}$ insulin, $100 \mathrm{U} / \mathrm{ml}$ penicillin, $100 \mu \mathrm{g} / \mathrm{ml}$ streptomycin, $2 \mathrm{mM}$ L-glutamine, $7.4 \mu \mathrm{g} / \mathrm{l}$ glucagon and 10\% FCS.

To complete HSC isolation from the supernatant generated by the first centrifugation, the remaining contaminating hepatocytes had to be removed. This was done by centrifuging at $100 \mathrm{~g}$ for $5 \mathrm{~min}$ at $4^{\circ} \mathrm{C}$ and transferring the supernatant to new centrifuge tubes at least twice or until no hepatocyte pellet can be seen after centrifugation. The supernatant free of hepatocytes was then centrifuged at $300 \mathrm{~g}$ for $5 \mathrm{~min}$ at $4^{\circ} \mathrm{C}$ to obtain a non-parenchymal cell pellet containing HSCs. The cell pellet was resuspended in a volume of degassed cell suspension buffer (Phosphate Buffered Saline (PBS) containing $2 \mathrm{mM}$ Ethylenediaminetetraacetic Acid (EDTA) and 0.5\% w/v Bovine Serum Albumin (BSA)) at least equal to the volume of the pellet before carrying out red blood cell lysis using a kit from Miltenyi Biotec (Teterow, Germany) according to the manufacturer's instructions. After red blood cell lysis, the cells were resuspended in cell suspension buffer and centrifuged at $300 \mathrm{~g}$ for $5 \mathrm{~min}$ at $4^{\circ} \mathrm{C}$. After resuspension in a small volume of cell suspension buffer, the cell suspension was filtered through a $70-\mu \mathrm{m}$ cell strainer (Miltenyi Biotec) and counted using a haemocytometer.

Next, magnetic-activated cell sorting (MACS) was carried out to positively select Epithelial Cell Adhesion Molecule (EpCAM)-expressing HSCs. There have been many markers used for HSC isolation in a variety of species. For this article, EpCAM was chosen as it has been shown to be consistently expressed in normal liver tissue (Schmelzer et al. 2007; Okabe et al. 2009). Briefly, cells were resuspended to a concentration of 50 million total cells per $0.3 \mathrm{ml}$ of cell suspension buffer before adding $0.1 \mathrm{ml}$ of FcR Blocking reagent (Miltenyi Biotec) followed by $0.1 \mathrm{ml}$ of EpCAM microbeads (Miltenyi Biotec) for each 50 million portion of cells. After swirling the cell suspension, the mixture was incubated at 4 to $8^{\circ} \mathrm{C}$ for $30 \mathrm{~min}$. After the incubation period, cells were washed in cell suspension buffer and resuspended with up to 200 million cells $\mathrm{ml}^{-1}$ cell suspension buffer before carrying out magnetic selection. Magnetic selection was carried out using the MiniMACSTM Separator with MS Columns (Miltenyi Biotec) according to the manufacturer's instructions.

After magnetic selection, the purified HSC suspension was centrifuged at $300 \mathrm{~g}$ for $5 \mathrm{~min}$ at $4{ }^{\circ} \mathrm{C}$. The pellet was resuspended in oval cell culture medium (William's Medium E containing $10 \%$ FCS, $10 \mathrm{mM}$ nicotinamide, $2 \mathrm{mM}$ L-glutamine, $0.2 \mathrm{mM}$ ascorbic acid, $20 \mathrm{mM}$ HEPES, $1 \mathrm{mM}$ sodium pyruvate, $17.6 \mathrm{mM}$ sodium bicarbonate, $14 \mathrm{mM} \alpha$-D-glucose, $100 \mathrm{nM}$ dexamethasone, 1X Insulin-Transferrin-Selenium, $0.5 \mu \mathrm{g} \mathrm{ml}^{-1}$ gentamicin, $10 \mathrm{ng} \mathrm{ml}^{-1}$ recombinant human epidermal growth factor, $10 \mathrm{ng} \mathrm{ml}^{-1}$ recombinant human hepatocyte growth factor and $10 \mathrm{ng} \mathrm{ml}^{-1}$ interleukin 6) and adhered on Corning ${ }^{\mathrm{TM}}$ Biocoat $^{\mathrm{TM}}$ collagen 1-coated plates for further experiments (Okabe et al. 2009).

Immunofluorescent staining Ten-micrometer cryosections on microscope slides (Marienfeld-Superior, Lauda-Königshofen, Germany) or cells adhered on 8-well culture slides coated with collagen were stained using immunofluorescence. In brief, the specimens were fixed for $10 \mathrm{~min}$ in $10 \%$ neutral-buffered formalin and subsequently permeabilised using $0.5 \%$ triton in PBS. After blocking with PBS containing $10 \%$ goat serum and $0.1 \%$ triton for a minimum of $1 \mathrm{~h}$ at room temperature, specimens were incubated with primary antibodies at $4{ }^{\circ} \mathrm{C}$ overnight. Primary antibodies used were against Cytokeratin 19 (CK19) (PA5-29582, Thermo Fisher Scientific, Waltham, MA), albumin (PA5-27707, Thermo Fisher Scientific) and Ki67 (ab15580, Abcam, Cambridge, UK). The primary antibodies were used at a dilution of 1:100, 1:100 and $0.5 \mu \mathrm{g}$ antibody $\mathrm{ml}^{-1}$ respectively. The next day, the specimens were incubated with the secondary antibodies conjugated with Alexa Fluor 488 (A-11034, Thermo Fisher Scientific) and 594 (A-11020, Thermo Fisher Scientific) for $1.5 \mathrm{~h}$. The 2 secondary antibodies were used at a dilution of 1:500. Finally, cover slips were mounted using Prolong Gold Antifade Mountant (Thermo Fisher Scientific).

CYP1A2 activity measurement CYP1A2 activity was determined using the P450-Glo CYP1A2 luminescent assay kit (Promega Corporation, San Luis Obispo, CA) according to the manufacturer's instructions.

Fluorescence-activated cell sorting To prepare cells for analysis, cells were fixed with $10 \%$ neutral-buffered formalin for $10 \mathrm{~min}$ at $37^{\circ} \mathrm{C}$ followed by chilling on ice for $1 \mathrm{~min}$. Next, cells were permeabilised by the slow addition of ice-cold $100 \%$ methanol to a final concentration of $90 \%$ methanol before incubation on ice for $30 \mathrm{~min}$. Cells were then blocked in PBS containing $0.5 \%$ BSA for $10 \mathrm{~min}$ at room temperature. Incubation of the cells with the primary anti-albumin antibody (PA5-27707, Thermo Fisher Scientific) at $5 \mu \mathrm{g}$ antibody $\mathrm{ml}^{-1}$ was done for $1 \mathrm{~h}$ followed by 30-min incubation with a secondary antibody conjugated to Alexa Fluor 488 (A-11034, Thermo Fisher Scientific) at $5 \mu \mathrm{g}$ antibody $\mathrm{ml}^{-1}$. Washing with PBS containing $0.5 \%$ BSA was carried out in between the key steps mentioned above.

Fluorescence-activated cell sorting (FACS) was carried out using a FACSCalibur (BD Biosciences, Heidelberg, Germany) and data collected was analysed using FlowJo version 10 (Flowjo LLC, Ashland, OR). 
Statistical analysis Values are presented as means \pm standard error of the mean. Two-tailed paired $t$ tests done using Spss Statistics (IBM, Armonk, NY) were used to identify significant differences $(P<0.05)$ between means.

\section{Results}

$\mathrm{CK}_{19^{+}}$cells express EpCAM in human normal and cirrhotic liver In order to validate the usage of $\mathrm{EpCAM}^{+}$as a selection marker for human HSCs in our laboratory, expression was examined in human normal and cirrhotic liver cryosections (Fig. 1). Similar to the DDC-fed mice, an increase in ductular structures formed by $\mathrm{EpCAM}^{+}$cells was seen in human cirrhotic liver (Fig. 1a). All these $\mathrm{EpCAM}^{+}$cells also expressed Cytokeratin 19 (CK19 (Fig. 1b)), a marker of HSCs and cholangiocytes. This marker expression pattern was also seen in normal liver, albeit with markedly less ductular structures present when compared with the cirrhotic liver (Fig. 1d-f). Thus, similar to the mouse model, all human HSCs that express CK19 also expressed EpCAM (Fig. 1c,f), meaning that EpCAM can be used as the selection marker.

Figure 1. EpCAM and CK19 colocalise in human liver. Immunofluorescent staining of EpCAM and CK19 in cirrhotic $(a-c)$ or in macroscopically normal liver $(d-f)$. EpCAM localisation is visualised in red in panels $(a)$ and $(d)$, while CK19 localisation is visualised in green in panels $(b)$ and $(e)$. Co-localised expression of EpCAM and CK19 can be seen in panel $(c)$ for cirrhotic liver and panel $(f)$ for normal liver. Scale bars in the figure indicate a length $100 \mu \mathrm{m}$.
Characterisation of isolated hepatocytes Characterisation of hepatocytes isolated in parallel with HSCs shows that the isolated hepatocytes had a high average viability of $79 \pm 2 \%$ with a yield of $5 \pm 1$ million hepatocytes per gram liver $(N=$ 11). Furthermore, phase contrast microscopy showed that the isolated hepatocytes exhibited key characteristics of hepatocytes; isolated cells were large polygonal cells with numerous binucleate cells (Fig. 2a). In addition, immunofluorescent staining showed that these isolated cells expressed hepatocyte marker albumin (Fig. 2b). Finally, these cells expressed a basal activity of CYP1A2 $\left(0.31 \pm 0.08 \mathrm{nmol}\right.$ luciferin $\mathrm{mg}^{-1}$ protein), which could be induced after treatment with $100 \mu \mathrm{M}$ of omeprazole to $2.48 \pm 0.37 \mathrm{nmol}$ luciferin $\mathrm{mg}^{-1}$ protein for $2 \mathrm{~d}$ (Fig. 2d). Thus, hepatocytes isolated using this method are suitable for further experiments.

Characterisation of isolated hepatic stem cells This isolation method yielded $1.2 \pm 0.2$ million live non-parenchymal cells per gram liver $(N=12)$ for the subsequent isolation of $\mathrm{EpCAM}^{+}$cells. After carrying out MACS, the yield of positively selected $\mathrm{EpCAM}^{+}$cells was $15,076 \pm 4307$ cells per gram liver $(N=12)$. Since relatively large pieces of liver were
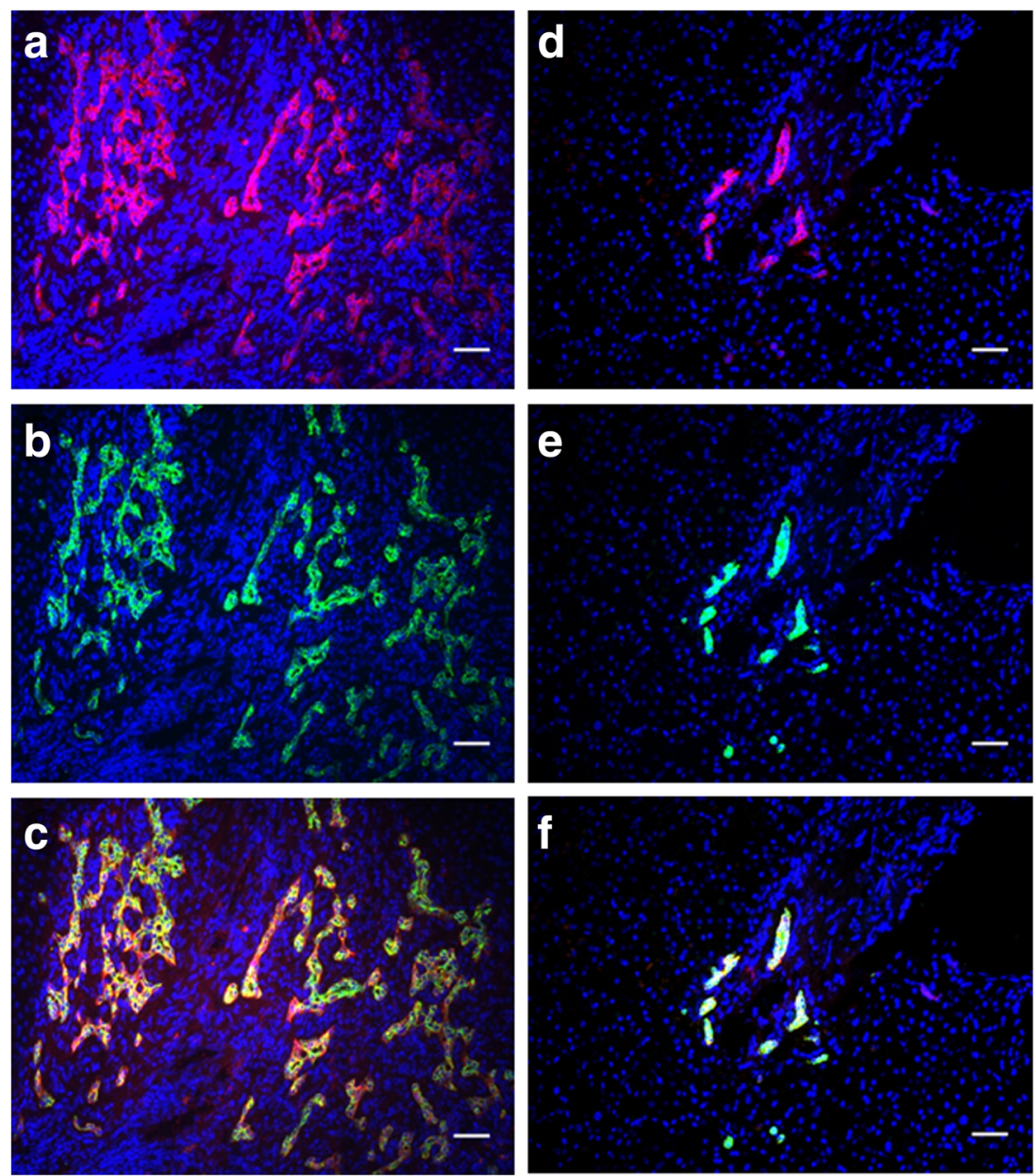
Figure 2. Hepatocyte

characterisation.(a)

Representative phase contrast image of hepatocytes adhered to collagen 1-coated plate $2 \mathrm{~d}$ after isolation. (b) Representative immunofluorescent image showing characteristic albumin (green) staining in hepatocytes with $(c)$ corresponding secondary antibody control image. Nuclei were counterstained blue using DAPI. (d) CYP1A2 activity was induced in hepatocytes after treatment with $100 \mu \mathrm{M}$ omeprazole for $48 \mathrm{~h}$. Values from 3 biological replicates are presented in the histogram. *Significantly different from control, $P<0.05$. Scale bars in the figure indicate a length $100 \mu \mathrm{m}$.
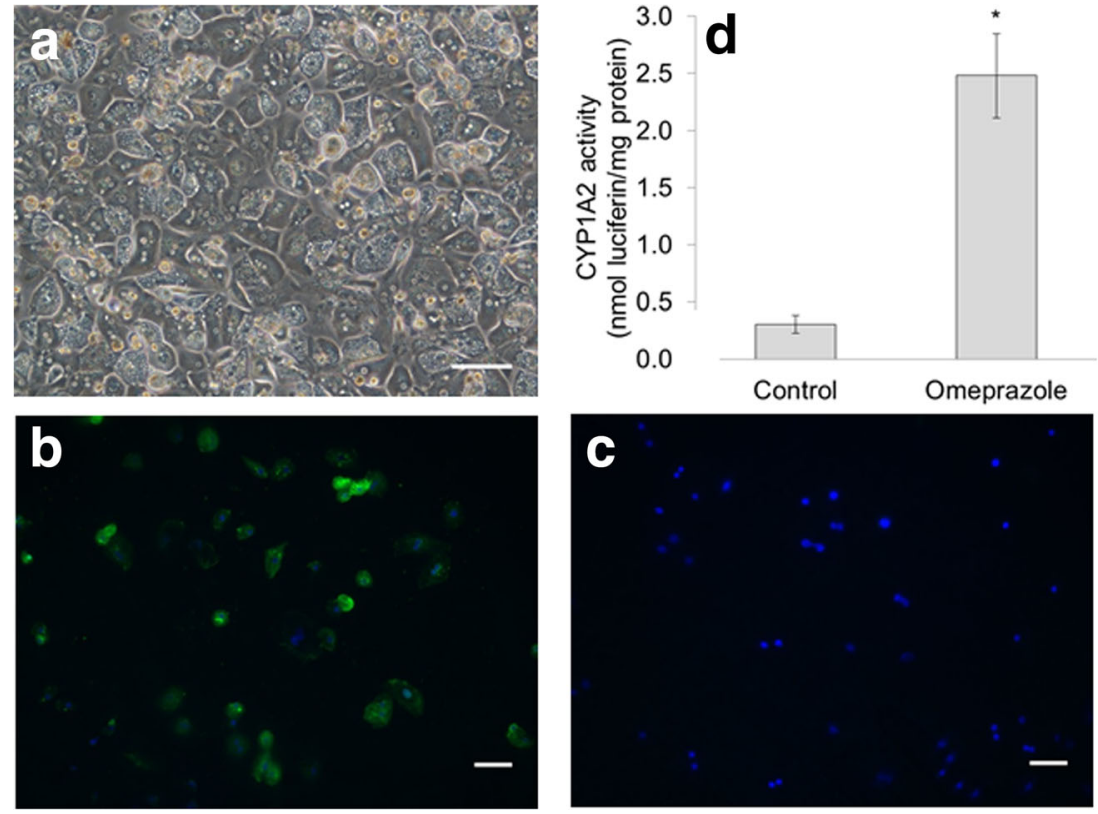

used for cell isolation, the total yield of $0.86 \pm 0.21$ million $\mathrm{EpCAM}^{+}$cells was sufficient for further experiments.
Immediately after isolation, $\mathrm{EpCAM}^{+}$cells were characterised by FACS. Figure $3 a$ shows the front and side
Figure 3. Characterisation of $\mathrm{EpCAM}^{+}$cells immediately after isolation. (a) Representative pseudocolor plot showing the forward and side scatter of the isolated $\mathrm{EpCAM}^{+}$cells. (b) Overlaid histograms showing control/unstained cells (filled black) and albumin ${ }^{+}$cells (dotted line). Ninety-eight percent of the isolated $\mathrm{EpCAM}^{+}$cells expressed albumin, a marker expressed by hepatic stem cells. (c)

Representative phase contrast image of hepatic stem cells $1 \mathrm{~d}$ after isolation showing characteristic oval nuclei and scant cytoplasm. The scale bar in the figure indicates a length $100 \mu \mathrm{m}$.
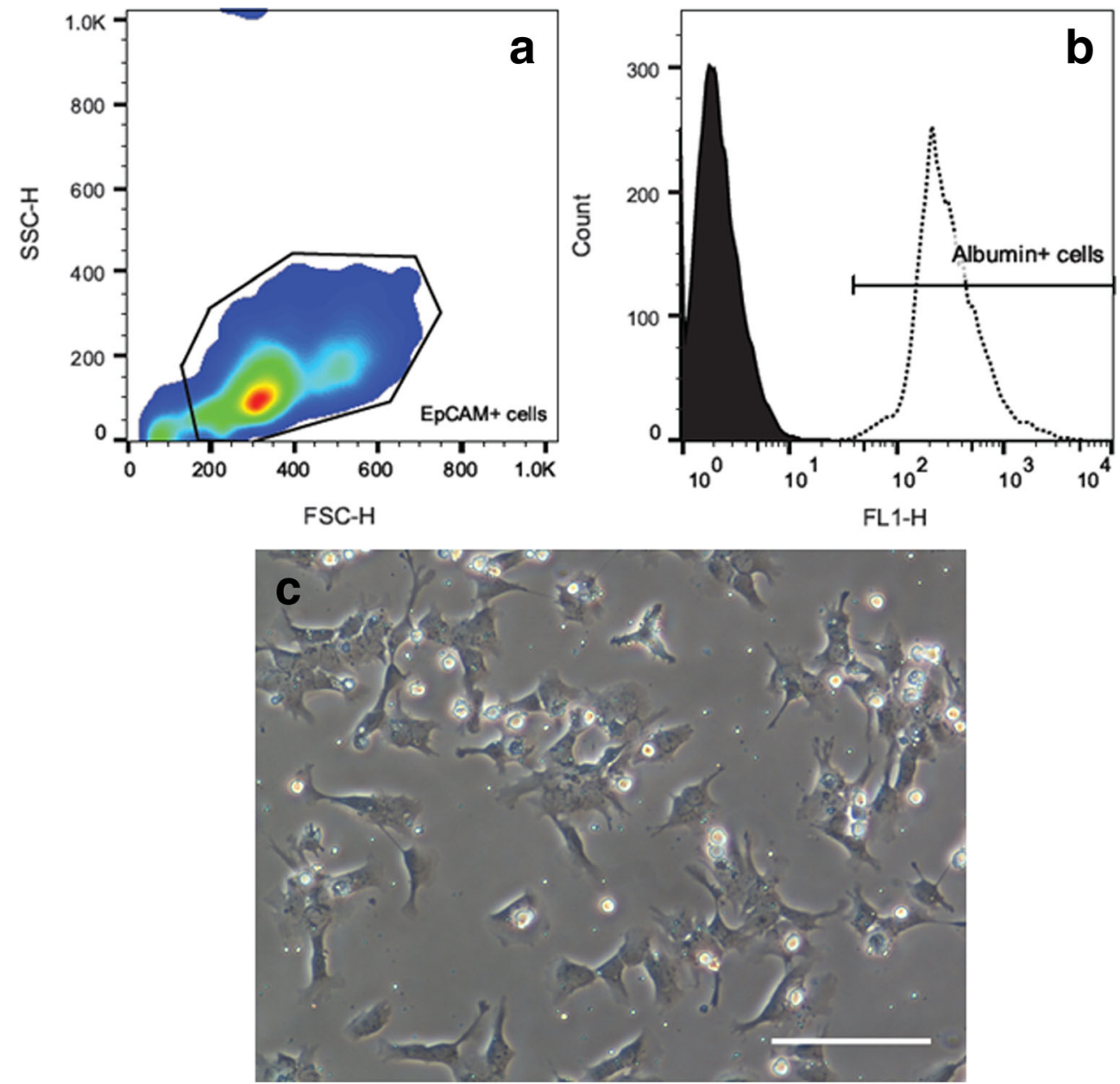
scatter of the population of $\mathrm{EpCAM}^{+}$cells. When examined for albumin expression, $98 \pm 1 \%$ of the cells were found to express this marker (Fig. 3b). Since we have established that EpCAM ${ }^{+}$ cells also express CK19, the co-expression of CK19 and albumin indicates that the isolated cells are a pure population of HSCs. Phase contrast images taken $1 \mathrm{~d}$ after isolation support this assertion as it can be seen that the isolated cells have ovoid nuclei and scant cytoplasm characteristic of HSCs (Fig. 3c). Furthermore, cultured cells maintained stem cell phenotype on day 5 of culture as evidenced by the co-expression of albumin (Fig. 4a) and CK19 (Fig. 4b) in Fig. 4c. In addition, all of these cells expressed Ki67 (Fig. 4e), a marker of proliferation. Cell proliferation is of note as it could promote the formation of iPSCs (Panopoulos et al. 2012), which is a common goal for many researchers who work with HSCs.

\section{Discussion}

Okabe et al. (Okabe et al. 2009) published a simple FACSbased method for the isolation of mouse HSCs through the selection of EpCAM ${ }^{+}$cells in normal and injured liver. Their publication reported that the yield of HSCs from mouse livers injured by a 3,5-diethoxycarbonyl-1,4-dihydro-collidine (DDC)-containing diet was more than 2-fold compared with normal livers (Okabe et al. 2009). DDC is a porphyrinogenic agent that causes chronic oxidative liver damage, hepatocyte ballooning and the formation of Mallory-Denk bodies (De Matteis et al. 1973; Snider et al. 2011). Further evidence that EpCAM is a suitable isolation marker comes from Schmelzer et al. (Schmelzer et al. 2007), who have used EpCAM selection to isolate HSCs from neonatal, pediatric and adult livers with the finding that neonatal and pediatric livers yield 2- to 3fold more $\mathrm{EpCAM}^{+}$cells. Although a lower HSC yield from normal livers has been reported by the above authors (Schmelzer et al. 2007; Okabe et al. 2009), we believe that it is important to optimise and present a method to isolate HSCs and hepatocytes from normal human livers using EpCAM marker selection. One of the reasons for this importance is that although many authors have generated iPSCs from dermal fibroblasts and peripheral blood cells with subsequent differentiation to hepatocytes, these studies either did not compare the iPSC-Heps to primary human hepatocytes or were not able to compare the iPSC-Heps to primary
Figure 4. Hepatic stem cell characterisation. Immunofluorescent labelling of (a) albumin (green) and (b) CK19 (red) in hepatic stem cells $5 \mathrm{~d}$ after isolation with the co-localised expression of albumin and CK19 shown in panel $(c)$. The corresponding secondary antibody control image is shown in panel (d). These cells express (e) proliferation marker Ki67 (green) in the nuclei making them appear cyan when compared with the corresponding $(f)$ secondary antibody control with blue nuclei. Nuclei are counterstained blue with DAPI. Scale bars in the figure indicate a length $100 \mu \mathrm{m}$.
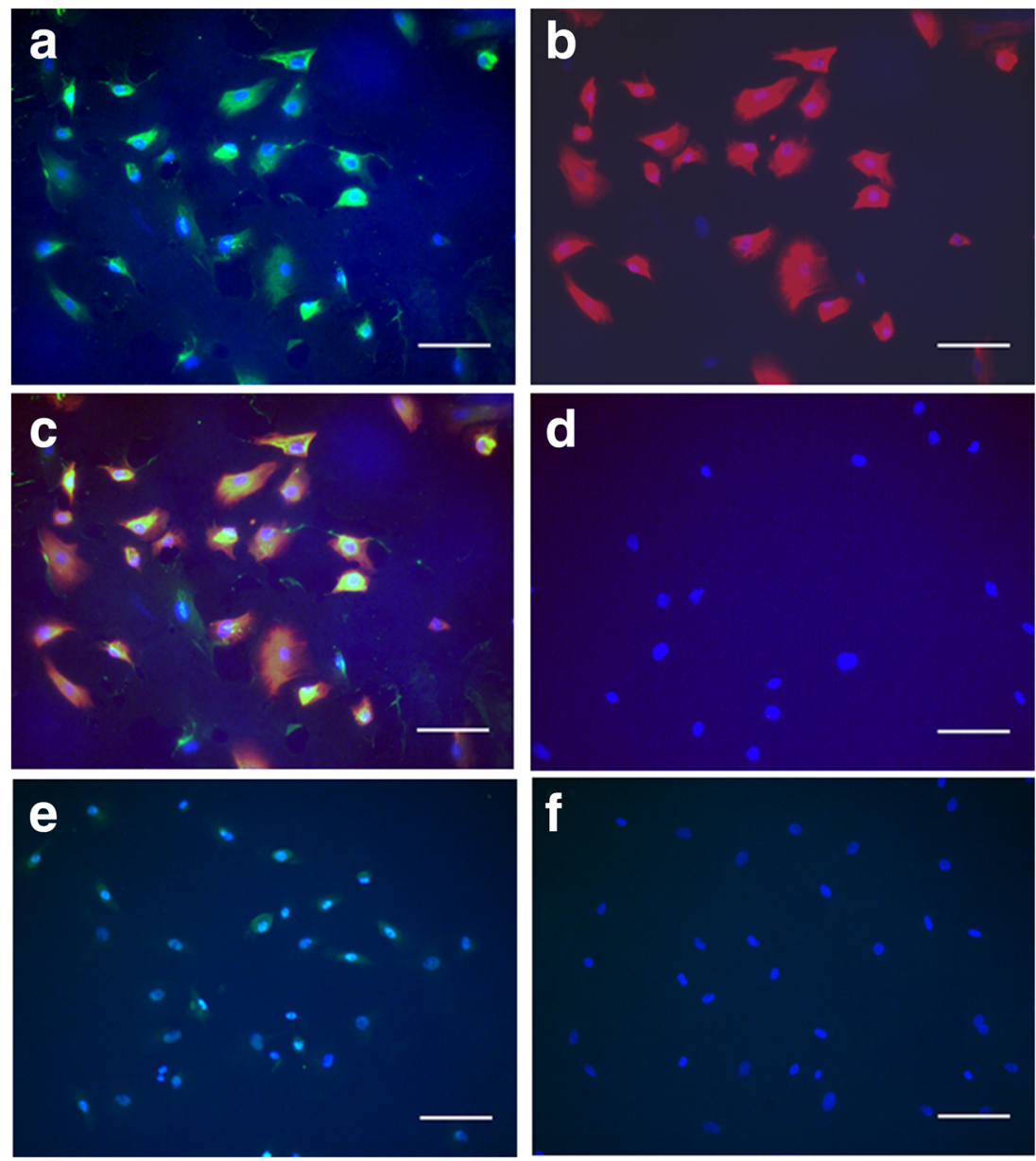
hepatocytes from the same donor (Ghodsizadeh et al. 2010; Kajiwara et al. 2012; Krueger et al. 2013; Ulvestad et al. 2013). With the aim of isolating HSCs and primary hepatocytes from the same liver, this method can provide a powerful tool to determine if hepatocytes derived from HSCs or iPSCs generated from HSCs can reproduce the key characteristics of hepatocytes from the same donor. If desired, iPSC-Heps derived from peripheral blood cells of the same donor can also be tested as it is generally possible to obtain a small volume of blood with written informed consent. This will allow researchers to identify the effects due to reprogramming to iPSCs and to understand the influence of different starting cell types for reprogramming. Another reason to publish this method is that although there are methods available to isolate HSCs, to our knowledge, there is no detailed protocol available for the isolation of high-quality HSCs and hepatocytes from the same donor.

\section{Conclusions}

In conclusion, a method for the concurrent isolation of hepatocytes and HSCs has been successfully established. The method presented here is relatively fast as no additional enzymatic digestion steps have been added after the 2-step collagenase perfusion of the liver piece was complete. This brings the isolation time required down to a manageable time of approximately $6 \mathrm{~h}$ as livers donated from elective surgeries are usually received between early to late afternoon due to the time needed for the operations.

The isolation of HSCs and hepatocytes from the same donor will allow for the first time benchmarking of differentiated hepatocytes to the isolated hepatocytes from the same donor. In addition, when reprogramming to iPSC is undesirable, HSCs can also be maintained in culture for a prolonged period (Wang et al. 2010) for differentiation to hepatocytes. Furthermore, the effects of reprogramming to iPSCs can also be compared using HSCs due to their amenability to culture and subsequent direct differentiation to hepatocytes.

Acknowledgements Donated human tissues were provided by the HTCR Foundation, a foundation under German civil law, which facilitates research with human tissue by providing an ethical and legal framework for prospective sample collection. We would like to thank the employees of the Biobank for their excellent technical assistance.

Authors' contributions SL, CB, AR and WT participated in the conception and the design of the study. SL and $\mathrm{CB}$ acquired and analysed the data. SL, CB, AR, WT, TS and KJ contributed to the interpretation of the data. All authors were involved in drafting or revising the manuscript and approved the final manuscript.

Funding information Open Access funding provided by Projekt DEAL. This work was financially supported by a Roche Postdoctoral Fellowship Grant.
Data availability The data used and/or analysed during the current study are available from the corresponding author on reasonable request and with permission from the authors in F. Hoffmann-La Roche Ltd.

\section{Compliance with ethical standards}

Conflict interest The authors declare that they have no competing interests.

Ethics approval and consent to participate Biospecimens were provided double-coded by the Biobank under the administration of the Human Tissue and Cell Research (HTCR) Foundation at the LudwigMaximilians-University (LMU). The framework of the HTCR Foundation, which includes written informed consent from all donors, has been approved by the ethics commission of the Faculty of Medicine in the LMU (number 025-12) and the Bavarian State Medical Association (number 11142).

Open Access This article is licensed under a Creative Commons Attribution 4.0 International License, which permits use, sharing, adaptation, distribution and reproduction in any medium or format, as long as you give appropriate credit to the original author(s) and the source, provide a link to the Creative Commons licence, and indicate if changes were made. The images or other third party material in this article are included in the article's Creative Commons licence, unless indicated otherwise in a credit line to the material. If material is not included in the article's Creative Commons licence and your intended use is not permitted by statutory regulation or exceeds the permitted use, you will need to obtain permission directly from the copyright holder. To view a copy of this licence, visit http://creativecommons.org/licenses/by/4.0/.

\section{References}

Berry MN, Friend DS (1969) High-yield preparation of isolated rat liver parenchymal cells: a biochemical and fine structural study. J Cell Biol 43:506-520

De Matteis F, Abbritti G, Gibbs AH (1973) Decreased liver activity of porphyrin-metal chelatase in hepatic porphyria caused by 3,5 diethoxycarbonyl-1,4-dihydrocollidine. Studies in rats and mice. Biochem J 134:717-727

Ghodsizadeh A, Taei A, Totonchi M, Seifinejad A, Gourabi H, Pournasr B, Aghdami N, Malekzadeh R, Almadani N, Salekdeh GH, Baharvand H (2010) Generation of liver disease-specific induced pluripotent stem cells along with efficient differentiation to functional hepatocyte-like cells. Stem Cell Rev 6:622-632

Kajiwara M, Aoi T, Okita K, Takahashi R, Inoue H, Takayama N, Endo H, Eto K, Toguchida J, Uemoto S, Yamanaka S (2012) Donordependent variations in hepatic differentiation from humaninduced pluripotent stem cells. Proc Natl Acad Sci U S A 109: $12538-12543$

Krueger WH, Tanasijevic B, Barber V, Flamier A, Gu X, Manautou J, Rasmussen TP (2013) Cholesterol-secreting and statin-responsive hepatocytes from human ES and iPS cells to model hepatic involvement in cardiovascular health. PLoS One 8:e67296

Lee SB, Seo D, Choi D, Park KY, Holczbauer A, Marquardt JU, Conner EA, Factor VM, Thorgeirsson SS (2012) Contribution of hepatic lineage stage-specific donor memory to the differential potential of induced mouse pluripotent stem cells. Stem Cells 30:997-1007

Lee SM, Schelcher C, Demmel M, Hauner M, Thasler WE (2013) Isolation of human hepatocytes by a two-step collagenase perfusion procedure. J Vis Exp. https://doi.org/10.3791/50615 
Okabe M, Tsukahara Y, Tanaka M, Suzuki K, Saito S, Kamiya Y, Tsujimura T, Nakamura K, Miyajima A (2009) Potential hepatic stem cells reside in EpCAM+ cells of normal and injured mouse liver. Development 136:1951-1960

Orloff J, Douglas F, Pinheiro J, Levinson S, Branson M, Chaturvedi P, Ette E, Gallo P, Hirsch G, Mehta C, Patel N, Sabir S, Springs S, Stanski D, Evers MR, Fleming E, Singh N, Tramontin T, Golub H (2009) The future of drug development: advancing clinical trial design. Nat Rev Drug Discov 8:949-957

Panopoulos AD, Yanes O, Ruiz S, Kida YS, Diep D, Tautenhahn R, Herrerias A, Batchelder EM, Plongthongkum N, Lutz M, Berggren WT, Zhang K, Evans RM, Siuzdak G, Izpisua Belmonte JC (2012) The metabolome of induced pluripotent stem cells reveals metabolic changes occurring in somatic cell reprogramming. Cell Res 22:168-177

Schmelzer E, Zhang L, Bruce A, Wauthier E, Ludlow J, Yao HL, Moss N, Melhem A, McClelland R, Turner W, Kulik M, Sherwood S, Tallheden T, Cheng N, Furth ME, Reid LM (2007) Human hepatic stem cells from fetal and postnatal donors. J Exp Med 204:19731987

Seglen PO (1973) Preparation of rat liver cells. 3. Enzymatic requirements for tissue dispersion. Exp Cell Res 82:391-398

Snider NT, Weerasinghe SV, Singla A, Leonard JM, Hanada S, Andrews PC, Lok AS, Omary MB (2011) Energy determinants GAPDH and NDPK act as genetic modifiers for hepatocyte inclusion formation. J Cell Biol 195:217-229

Ulvestad M, Nordell P, Asplund A, Rehnstrom M, Jacobsson S, Holmgren G, Davidson L, Brolen G, Edsbagge J, Bjorquist P, Kuppers-Munther B, Andersson TB (2013) Drug metabolizing enzyme and transporter protein profiles of hepatocytes derived from human embryonic and induced pluripotent stem cells. Biochem Pharmacol 86:691-702

Wang P, Cong M, Liu TH, Yang AT, Cong R, Wu P, Tang SZ, Xu Y, Wang H, Wang BE, Jia JD, You H (2010) Primary isolated hepatic oval cells maintain progenitor cell phenotypes after two-year prolonged cultivation. J Hepatol 53:863-871 